\title{
Identification of molecular markers for oocyte competence in bovine cumulus cells
}

\author{
E. O. Melo* , D. M. Cordeiro ${ }^{\dagger}$, R. Pellegrino ${ }^{\ddagger}$, Z. Wei ${ }^{\S}$, Z. J. Daye ${ }^{\Uparrow}$, R. C. Nishimura ${ }^{\dagger}$ and M. A. N. Dode* \\ *Embrapa- Genetic Resources and Biotechnology, Brasília, DF 70770-917, Brazil. †School of Agriculture and Veterinary Medicine, University \\ of Brasilia, Brasília, DF 70910-900, Brazil. 'Center for Applied Genomics, The Children's Hospital of Philadelphia, Philadelphia, PA 19104, \\ USA. ${ }^{\S}$ Department of Computer Science, New Jersey Institute of Technology, Newark, NJ 07102, USA. "Division of Epidemiology and \\ Biostatistics, University of Arizona, Tucson, AZ 85721, USA.
}

\section{Summary}

\begin{abstract}
Cumulus cells (CCs) have an important role during oocyte growth, competence acquisition, maturation, ovulation and fertilization. In an attempt to isolate potential biomarkers for bovine in vitro fertilization, we identified genes differentially expressed in bovine CCs from oocytes with different competence statuses, through microarray analysis. The model of follicle size, in which competent cumulus-oocyte complexes (COCs) were recovered from bigger follicles $(\geq 8.0 \mathrm{~mm}$ in diameter) and less competent ones from smaller follicles (1-3 mm), was used. We identified 4178 genes that were differentially expressed $(P<0.05)$ in the two categories of CCs. The list was further enriched, through the use of a 2.5 -fold change in gene expression as a cutoff value, to include 143 up-regulated and 80 downregulated genes in CCs of competent COCs compared to incompetent COCs. These genes were screened according to their cellular roles, most of which were related to cell cycle, DNA repair, energy metabolism, metabolism of amino acids, cell signaling, meiosis, ovulation and inflammation. Three candidate genes up-regulated (FGF11, IGFBP4, SPRY1) and three down-regulated (ARHGAP22, COL18A1 and GPC4) in CCs from COCs of big follicles $(\geq 8.1 \mathrm{~mm}$ ) were selected for $\mathrm{qPCR}$ analysis. The selected genes showed the same expression patterns by qPCR and microarray analysis. These genes may be potential genetic markers that predict oocyte competence in in vitro fertilization routines.
\end{abstract}

Keywords cattle, gene expression, microarray, oocyte quality

\section{Introduction}

Despite great improvements in assisted reproductive technology (ART), the success of in vitro embryo production remains relatively low. Most of the oocytes used to produce in vitro embryos are recovered from small follicles $(<6 \mathrm{~mm}$ in diameter), forming a heterogeneous population that must be matured in vitro. Since the original in vitro maturation (IVM) experiments (Heilbrunn et al. 1939), the process by which the most competent oocytes are selected to produce blastocysts remains similar and is still based on morphological aspects of the oocyte cytoplasm and the number of layers and compaction of cumulus cells (CCs) attached to the oocyte surface (Armstrong 2001; Krisher 2003; Lonergan et al. 2003; Coticchio et al. 2004). However, there is

Address for correspondence

E. O. Melo, Embrapa- Genetic Resources and Biotechnology, Brasília, DF, 70770-917, Brazil.

E-mail: eduardo.melo@embrapa.br

Accepted for publication 18 July 2016 increasing evidence that these morphological criteria are insufficient to precisely distinguish oocytes of high and low competence (Krisher 2003; Lonergan et al. 2003; Coticchio et al. 2004). Therefore, lack of full competence is a major factor responsible for the lower blastocyst rate when in vitro matured oocytes are used for ARTS as compared to the in vivo matured oocytes (Dieleman et al. 2001; Humblot et al. 2005; Assidi et al. 2008). Therefore, to improve IVM results and ART outcomes, a means to select the most competent oocytes is of great importance. Despite the accumulation of a great deal of knowledge obtained through IVM research, it is necessary to find more precise parameters to select the best quality oocytes to produce an elevated number of high quality blastocysts.

The competence of the oocyte to produce high-quality blastocysts is acquired gradually during folliculogenesis by cellular and molecular events that provide the oocyte with the capacity to complete meiotic divisions, to be fertilized and to develop into a viable embryo (Fair 2003; Coticchio et al. 2004). The information about the molecular events needed for the acquisition of competence that takes place 
during the final steps of folliculogenesis just before ovulation is dispersed and incomplete (Assidi et al. 2008; Hamel et al. 2008; Bessa et al. 2013; Bunel et al. 2014; Yerushalmi et al. 2014). Most of the data describing the crucial steps of follicular development come from gene expression studies using oocytes with different degrees of competence. Although some differences in gene expression levels are already associated with oocyte developmental competence in cattle (Donnison \& Pfeffer 2004; Fair et al. 2004; Dode et al. 2006; Misirlioglu et al. 2006; Mourot et al. 2006; Patel et al. 2006; Racedo et al. 2007; Caixeta et al. 2009; Mamo et al. 2011; Labrecque et al. 2013), these changes cannot be routinely used in ARTs as molecular markers for developmental competence due to invasive methods.

During oogenesis, the somatic cells that surround the oocyte proliferate and differentiate into CCs, which are metabolically coupled to the oocyte, forming the cumulusoocyte complexes (COCs) (van den Hurk \& Zhao 2005). The CCs remain in strong contact with the oocyte, maintained by cytoplasmic bridges called GAP-junctions as well as through justacrine and paracrine signaling networks (Albertini et al. 2001; Vozzi et al. 2001; Tanghe et al. 2002; Webb et al. 2002; Gilchrist et al. 2004). This intense bidirectional communication between the CCs and the oocyte is maintained during all phases of folliculogenesis and is essential for the acquisition of oocyte competence that is required for blastocyst development (Fair 2003; Gilchrist et al. 2004; Assidi et al. 2008; Regassa et al. 2011). Consequently, CCs may reflect oocyte quality and can be used for oocyte selection. Indeed, the physiological intimacy between the oocyte and CCs makes the latter a valuable source of molecular information, beyond the fact that CCs can be easily sampled before the IVM procedure without compromising oocyte viability (Assou et al. 2010; Huang \& Wells 2010; Gebhardt et al. 2011; Ekart et al. 2013; Iager et al. 2013; Bunel et al. 2015). Therefore, the gene expression profile of CCs may be a valuable source of genetic markers for oocyte competence and have a potential impact on the improvement of several ARTs (Gilchrist \& Thompson 2006; Gebhardt et al. 2011; Ekart et al. 2013; Iager et al. 2013; Bunel et al. 2015).

An informative model used by many research groups to assess the level of oocyte competence has been follicle size (Donnison \& Pfeffer 2004; Lequarre et al. 2005; Mourot et al. 2006; Caixeta et al. 2009; Fagundes et al. 2011; Bessa et al. 2013; Franco et al. 2014). In a previous study, we showed that oocytes obtained from follicles $1-3 \mathrm{~mm}$ in diameter are significantly less competent in producing blastocysts than are oocytes obtained from follicles $\geq 8 \mathrm{~mm}$ in diameter (Caixeta et al. 2009). In the present study, we used the same model to compare the gene expression profile of more than 23000 bovine transcripts between the CCs obtained from size-incompetent COCs $(1-3 \mathrm{~mm})$ and sizecompetent COCs $(\geq 8 \mathrm{~mm})$. We found substantial differences in the expression of several gene clusters representing distinct metabolic pathways such as energy metabolism, cell signaling, cell cycle, DNA repair, meiosis and inflammation. Among these gene clusters, we selected six genes from the same biochemical pathway (ARHGAP22, COL18A1, GPC4, FGF11, IGFBP4, SPRY1) based on their physiological roles as candidate biomarkers for bovine oocyte competence. We compared the relative expression of these genes in CCs obtained from size-incompetent COCs and size-competent COCs by qPCR. This approach offered several candidate genes for oocyte quality ranking that could be employed for direct selection prior to IVM procedures. A more accurate selection of competent oocytes will certainly improve in vitro embryo production in the near future for both human or livestock in vitro-produced embryos (Fagundes et al. 2011; Gebhardt et al. 2011; Ekart et al. 2013; Iager et al. 2013; Bunel et al. 2014, 2015; Franco et al. 2013). We aimed to find a marker that could allow us to predict, once COCs are removed from the follicles, which one is capable of becoming a blastocyst. Also, these potential biomarkers can be useful as a tool for the improvement of in vitro fertilization (IVF) and embryo culture media in order to increase the production and quality of the blastocysts.

\section{Materials and methods}

Unless otherwise indicated, all chemicals were purchased from Sigma Aldrich.

\section{Animals}

In our study, only ovaries collected at a slaughterhouse were used; therefore, this research was not submitted for ethics committee approval. In Brazil, slaughter of bovines is regulated by the Ministry of Agriculture by law number 7889 from 1989, which regulates the sanitary inspection and industrial production of animal products. The regulation regarding the collection and commercialization of semen is under law number 6446 from 1977, which regulates the inspection and monitoring of industrial semen production from domestic animals.

\section{Cumulus-oocyte complex recovery and storage}

Ovaries from crossbred cows (Bos taurus indicus $\times$ Bos taurus taurus) were collected immediately after slaughter and transported to the laboratory in a saline solution $(0.9 \%$ $\mathrm{NaCl})$ supplemented with penicillin $\mathrm{G}(100 \mathrm{IU} / \mathrm{ml})$ and streptomycin sulfate $(100 \mathrm{mg} / \mathrm{ml})$ at $35-37^{\circ} \mathrm{C}$. The follicles were dissected from the ovarian cortex using scissors, scalpels and tweezers in TCM-199 medium supplemented with Hank's salts and $10 \%$ fetal calf serum (GIBCO BRL) at $36{ }^{\circ} \mathrm{C}$. Follicles were measured using a graduated eyepiece (OSM-4; Olympus) and then classified morphologically into two groups according to their diameter: $1.0-3.0 \mathrm{~mm}$ or $\geq 8.0 \mathrm{~mm}$. The criteria used for follicle selection included: (i) 
the presence of extensive and fine vascularization; (ii) a shiny and translucent appearance; (iii) after follicular rupture, the presence of granulose cells with a regular and healthy appearance; and (iv) no free-floating particles in the follicular fluid. Only COCs with a homogeneous granulated cytoplasm and at least three layers of compact of CCs were used in the present study. The selected COCs were transferred to a 50- $\mu$ l droplet of phosphate-buffered saline, and the CCs were mechanically removed by repeated pipetting. After cumulus collection, they were transferred to a $0.2-\mathrm{ml}$ tube and centrifuged twice for $2 \mathrm{~min}$ at $700 \mathrm{~g}$. The supernatant was removed, and $2 \mu \mathrm{l}$ of RNAlater (Applied Biosystems) was added to the pellet, which was then stored at $-20^{\circ} \mathrm{C}$ until RNA extraction. For each follicle size group, three replicas of pooled CCs corresponding to 30 oocytes were stored for RNA extraction and subsequent microarray assays, and four independent replicates corresponding to 20 oocytes were stored for RNA extraction for subsequent qPCR assays.

\section{RNA extraction and cDNA synthesis}

Total RNA was extracted from pools of CCs using the RNeasy Plus Micro Kit (QIAGEN), according to the manufacturer's instructions. The extracted RNA was subjected to reverse transcription reaction with SuperScript III (200 U/ $\mu \mathrm{l}$; Invitrogen) and Oligo-dT primer (Invitrogen) according to the manufacturer's instructions. After extraction, the RNA samples were evaluated using an Agilent 2100 Bioanalyzer (Agilent Technologies), and samples with a ratio integrity $>9.0$ were used for microarray experiments.

\section{Microarray and data analysis}

The cDNA synthesis, amplification, biotin labeling, chip hybridizations, chip scanning and data collection were performed by the AFIP-Molecular Core facility (www.afip. com.br/principal.asp) using the Affymetrix microarray platform and the GeneChip Bovine Genome Array (Affymetrix, Inc.), which contains 24027 bovine probes corresponding to 19000 unigene clusters. One hundred nanograms of total RNA was amplified with a GeneChip 3' IVT Express aRNA amplification kit (Affymetrix, Inc.), according to the manufacturer's instructions, to produce enough RNA $(1-2 \mu \mathrm{g})$ for the hybridizations. Six chips were hybridized with three biological replicates for each treatment (CCs from small and large follicles). The microarray quality controls were performed using distinct platforms including the application of R/AFFY and R/AFFYQCREPORT. The correction algorithm robust multichip average (RMA) was used for normalization, and relative log expression (RLE) and normalized unscaled standard error (NUSE) were used to calculate the relevant statistics (Brettschneider et al. 2008). The functional classification of the genes and metabolic pathway analysis were performed using Database for Annotation, Visualization and Integrated Discovery (DAvID; http://david.abcc.ncifcrf.gov) software and the Kyoto Encyclopedia of Genes and Genomes (KEGG; www.genome.jp/ $\mathrm{kegg} / \mathrm{kegg} 1 . \mathrm{html}$ ) database. Probes showing significant fold change in gene expression $(P<0.05)$ were listed, and the metabolic pathway analysis was carried out with the probes indicating a fold change of $\geq 2.5$ (up or down; GEO accession no. GSE65269).

\section{Real-time RT-PCR (qPCR)}

Six genes were selected from the microarray experiment according to their biochemical pathway (cell cycle) and their possible role in oocyte competence; these genes included fibroblast growth factor 11 (FGF11), insulin like growth factor binding protein 4 (IGFBP4), sprouty RTK signaling antagonist 1 (SPRY1), Rho GTPase activating protein 22 (ARHGAP22), collagen type XVIII alpha 1 chain (COL18A1) and glypican 4 (GPC4). Real-time RT-PCR analysis was performed using Fast SYBR Green Master Mix (Applied Biosystems). Reactions were performed in a volume of $25 \mu \mathrm{l}$. The PCR cycling conditions were as follows: $95^{\circ} \mathrm{C}$ for $20 \mathrm{~s} ; 50$ cycles of denaturing at $95^{\circ} \mathrm{C}$ for $3 \mathrm{~s}$ and annealing at $60^{\circ} \mathrm{C}$ for $30 \mathrm{~s}$. Primer sequences, fragment size, annealing temperature and primer concentrations for each gene are listed in Table S1. Reactions were performed in quadruplicate for each gene with an amplification efficiency of $>90 \%$ for each primer pair. The expression of the endogenous control genes peptidylprolyl isomerase A (PPIA) (former name: cyclophilin A) and glyceraldehyde-3-phosphate dehydrogenase (GAPDH) were quantified, but only GAPDH expression was used to normalize target genes due to its greater expression stability than PPIA. The relative abundance of each gene was calculated using the $\Delta \Delta \mathrm{Ct}$ method with efficiency correction (Pfaffl 2001).

\section{Statistical analysis}

The microarray data were analyzed using the following R/ANOVA model (Wolfinger et al. 2000):

$$
Y_{i j k l}=m+T_{i}+A_{j(i)}+G_{k}+T G_{i k}+e_{i j k},
$$

where $Y$ is the normalized intensity value; $m$ is the general median; $A, T$ and $G$ represent the array principal effect, treatment and gene respectively; $T G$ is the effect of gene and treatment interaction; $e$ is the random error; $i$ is the gene spot intensity and $k$ is the array. The $F_{S}$ test was applied combining the global data and the specific data for each gene using a shrinkage factor (Cui \& Churchill 2002). The false discovery rate was used to adjust the false-positive rate and was fixed at $5 \%$.

The gene expression data collected by qPCR were analyzed using the Mann-Whitney test. All statistical analyses were performed using PROPHET software version 
5.0 (BBN Systems and Technologies). Results are presented as the mean \pm SEM, with $P<0.05$ indicating significance.

\section{Results}

\section{Microarrays analysis}

The microarray hybridizations were within the desirable standard, with a probe hybridization rate over $56 \%$ and a low level of background (34-55 points). The RMA Express parameter presented quality limits between 95\% and 99\% for median and interquartile range and RLE and NUSE values (Fig. 1a). Each of the six arrays were within the quality parameters required for statistical analysis. The array analysis showed 4178 differentially expressed genes $(P<0.05)$, of which 2298 were down-regulated and 1880

(a)

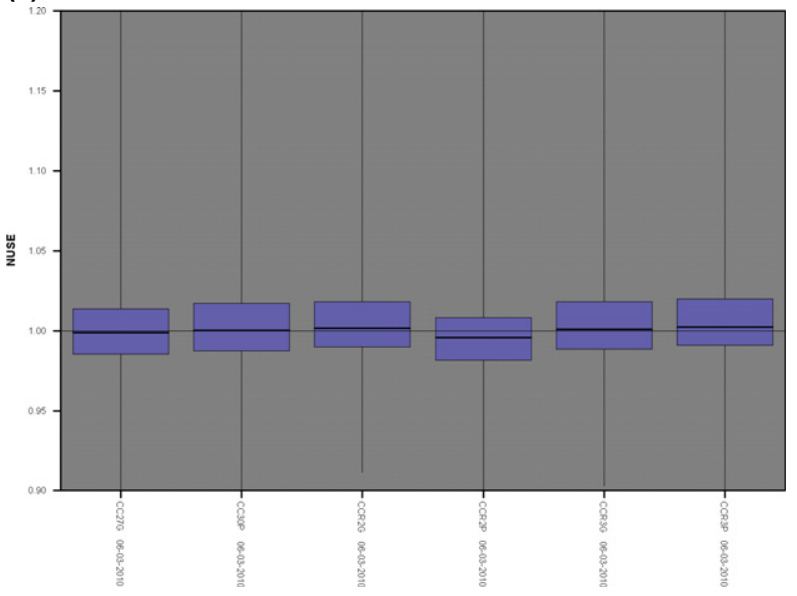

(b)

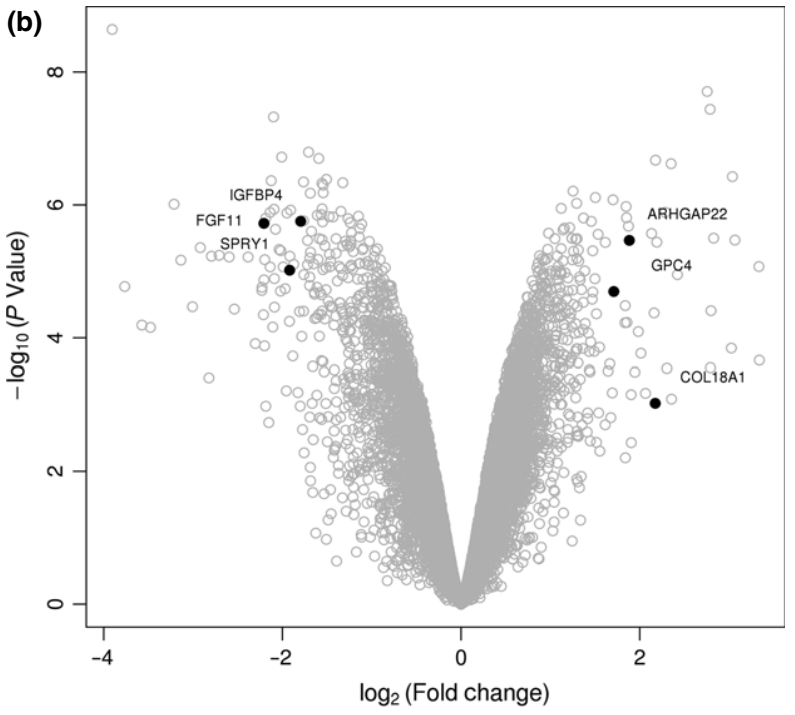

Figure 1 (a) NUSE: normalized unscaled standard errors of the six array chips. (b) Significance dispersion plot of mRNA transcripts from cumulus cells, $-\log 10(P$-value), and the fold changes $(\log 2)$ in gene expression between the small $(1-3 \mathrm{~mm})$ and large $(\geq 8.1 \mathrm{~mm})$ follicle groups. The genes used in qPCR analysis are displayed in black. were up-regulated in the CCs from large follicles $(\geq 8.0 \mathrm{~mm}$ in diameter) compared to CCs from small follicles (1-3 mm in diameter). The fold change in the expression of each gene was plotted on a volcano chart to present the dispersion of gene expression and significance (Fig. 1b).

\section{Annotation of gene function}

All differentially expressed genes were classified according to their function using the KEGG database as part of the DAVID software package, and changes in gene expression were presented relative to the CCs from bigger follicles. They grouped into representative pathway categories such as cell cycle, amino acid metabolism, cell signaling, DNA repair, energy metabolism, meiosis and ovulation/inflammation (Table S2). As shown, most of the metabolic pathway categories (cell cycle, cell signaling and energy metabolism) were present in both treatments. Three categories (DNA repair, meiosis and amino acid metabolism) were represented only in the down-regulated expression group, whereas the ovulation/inflammation representative genes were present only in the list of up-regulated genes (Fig. 2). Moreover, $20 \%$ and $27 \%$ of the genes in the up-regulated and down-regulated groups respectively were annotated as having an unknown function according to DAVID software. A list of differentially expressed genes, including 143 upregulated and 80 down-regulated genes with a fold change
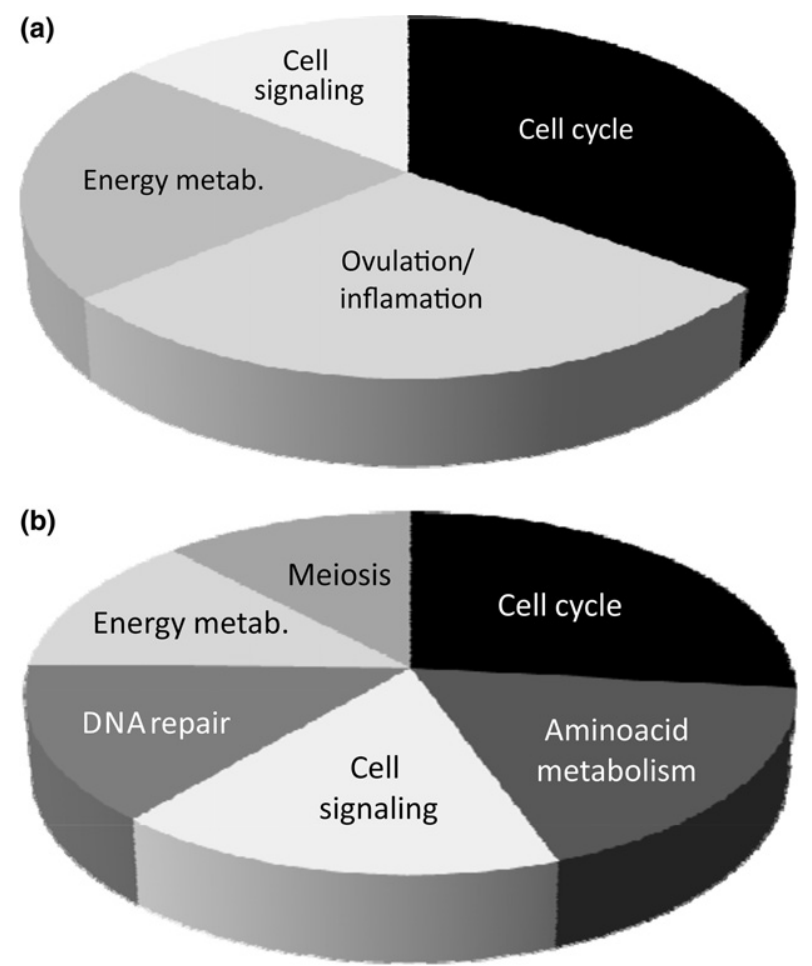

Figure 2 Functional classification of (a) up-regulated and (b) downregulated genes, according to the KEGG database. The big follicle group ( $\geq 8.1 \mathrm{~mm}$ in diameter) was used as a reference. 


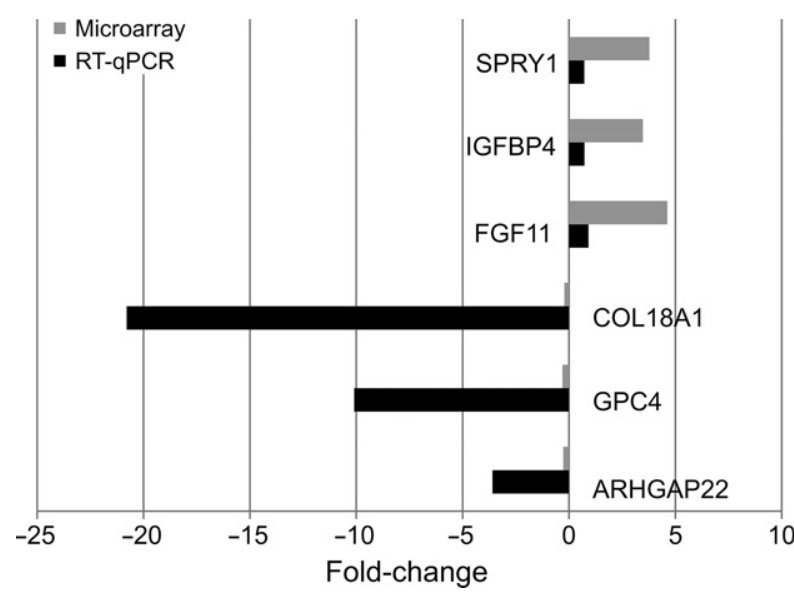

Figure 3 Fold-change values of differential gene expression in cumulus cells (Bos taurus $\times$ Bos indicus) derived from follicles of 1-3 mm $(P<0.05)$ as detected by the microarray (grey bars) or qPCR (black bars). SPRY1, sprouty RTK signaling antagonist 1; IGFBP4, insulin-like growth factor binding protein 4; FGF11, fibroblast growth factor 11; ARHGAP22, Rho GTPase activating protein 22; COL18A1, collagen type XVIII alpha 1 chain; GPC4, glypican 4.

interval of $\geq 2.5$ is shown (Tables S3 \& S4 respectively). Notably, an elevated number $(n=56)$ of non-annotated genes/probes was present in the two groups. A smaller number of down-regulated genes (with a fold change of $\geq 2.5$ ) was observed and also showed a lower maximum fold change $(10 \times)$ compared to the group of up-regulated genes (maximum $15 \times$ ).

\section{Candidate genes selection and qPCR}

Using the list of genes with an expression change of $\geq 2.5$ fold, we selected three up-regulated genes (FGF11, IGFBP4 and SPRY1) and three down-regulated genes (ARHGAP22, COL18A1 and GPC4) as candidates for biomarkers of COC quality. These six genes were subjectively selected using the physiological function of each gene as the main criterion. The expression change for each of the selected genes was validated by qPCR and matched the pattern seen by microarray analysis (Fig. 3). qPCR was chosen for expression analysis of the selected genes, as it is the most adequate technique to measure the expression of candidate genes during the IVP biopsy routine. GAPDH and PPIA were used as housekeeping gene controls due to their documented performance as stable controls for cattle oocyte and embryos (Goossens et al. 2005; Bettegowda et al. 2006; Hatzirodos et al. 2014; Luchsinger et al. 2014).

\section{Discussion}

In the present study, we analyzed the relative abundance of genes potentially involved in oocyte competence using a follicle size model (Caixeta et al. 2009). This model is based on the well-established relationship between follicle size and oocyte developmental competence (Lequarre et al. 2005; Mourot et al. 2006; Caixeta et al. 2009). Although attempts to identify potential biomarkers for oocyte quality using the follicle size model have been reported in the literature, they differ from the present study in various aspects. For example, a gene expression profile of the oocyte was not performed in the present study; instead, potential marker genes were screened using CCs as the source, because CCs can be sampled using a noninvasive method. Moreover, a specific bovine microarray was used for the first time as a high-throughput method to analyze the gene expression profile of the crossbred B. taurus indicus $\times B$. taurus taurus as COC donors, using the follicular size model. The choice of COCs obtained from different-size follicle groups was based on the lower competence of COCs of up to $3 \mathrm{~mm}$ in diameter to produce blastocysts compared to COCs from bigger follicles ( $\geq 8.0 \mathrm{~mm}$ ) (Caixeta et al. 2009).

The inference of oocyte quality obtained by analyzing the gene expression and physiological state of CCs is based on the metabolic interaction between the oocyte and the CCs through bidirectional communication by GAP-junctions and plasmodesmas projections (Allworth \& Albertini 1993; Regassa et al. 2011) as well as indirectly by an intense paracrine signaling network (Paulini \& Melo 2011). This tight metabolic interdependence between the oocyte and the CCs can be used for an indirect and non-invasive evaluation of oocyte competence prior to IVP (Cillo et al. 2007; Feuerstein et al. 2007; Assidi et al. 2008; Bettegowda et al. 2008; Gebhardt et al. 2011; Ekart et al. 2013; Iager et al. 2013; Bunel et al. 2014, 2015). In this study, 19000 bovine unigene clusters were investigated, revealing interesting results and interpretations. Microarray analysis unveiled 4178 differentially expressed genes (Table S5), most of which (54\%) were down-regulated in CCs from big follicles ( $\geq 8.0 \mathrm{~mm}$ ). This result is expected, as bigger follicles are prone to ovulation; thus, the gene expression activity should be lower (van Montfoort et al. 2008; Assidi et al. 2010). According to the KEGG database annotation, the downregulated genes involve more metabolic pathways (six) than do those that were up-regulated (four) (Fig. 2). Some of the genes are common between the two groups (cell cycle, cell signaling and energy metabolism), and others are exclusive to the down-regulated (meiosis, DNA repair and amino acid metabolism) or up-regulated (ovulation/inflamation) categories. This is consistent with the morphological and physiological events that occur within follicles during growth and maturation, leading to ovulation and demanding intense network signaling to orchestrate cell division and differentiation (Assidi et al. 2010). The vigorous division of follicle cells in small follicles may explain the $14 \%$ increase in the expression of genes involved with DNA repair activity.

The ovulation/inflammation pathway represents $29 \%$ of the genes up-regulated exclusively in CCs from the bigger follicle group. During the final steps of follicular growth, while the COCs are preparing to ovulate, the ovarian 
epithelium ruptures, resembling an inflammatory process (Hernandez-Gonzalez et al. 2006; Russell \& Robker 2006; Richards 2007). Moreover, the immune cells that participate during the inflammatory response are capable of interferon secretion, which has an important role in the physiology of female organs (Brännström et al. 1995; Wolf et al. 2003; Gérard et al. 2004; Bauersachs et al. 2008; Asirvatham et al. 2009). Several genes related to interferon production were found to be up-regulated in CCs from big follicles in our experiments. Additionally, the data suggest that $\alpha$-interferon is involved in the differentiation of preovulatory follicles in rats (Lee et al. 2009), corroborating our findings.

During maturation, COCs are prepared for radical changes in the source of energy that occurs after ovulation, during fertilization and during initial embryo development (Brison 1999; Thompson et al. 2006; Su et al. 2007). Therefore, the high expression of genes grouped in the energy metabolism category in both experimental groups is comprehensive. However, amino acids are a relevant source of energy for oocytes during maturation and after ovulation and must be stored during late COC growth phase (RoseHellekant et al. 1998; Hernandez-Gonzalez et al. 2006). Therefore, the intense activity (18\%) of genes involved in amino acid metabolism found in CCs from small COCs is also expected. Oocyte maturation is characterized by the completion of the first meiotic division that was held at metaphase II during initial follicle formation (Fair et al. 2007). After follicular deviation, the oocyte must be prepared to resume meiotic division, and the CCs must signal to the oocyte to initiate the accumulation of factors involved in the induction of meiosis. In the present study, these factors represent $12 \%$ of the genes up-regulated in CCs from growing small follicles.

In agreement with the literature, our data also have identified several genes differentially expressed in CCs derived from follicles of distinct developmental competence, including FSHR, EGFR and GHR (Caixeta et al. 2009); CTSB (Bettegowda et al. 2008); TNFAIP6, TRIB2 and ERRFI1 (Assidi et al. 2010); and DPP8 (Assidi et al. 2011). More recently several articles were published describing the use of CC's gene expression profile as a physiological marker of oocyte competence and quality in cattle (Tesfaye et al. 2009; Regassa et al. 2011; Bunel et al. 2014, 2015) and human (Gebhardt et al. 2011; Ekart et al. 2013; Iager et al. 2013; Xu et al. 2015). Despite their differences in the origin of CCs (cattle or human), experimental design and the microarray platform used, some genes are repeatedly present in the lists of differentially expressed in CC from high-competent COCs in several microarray experiments: HAS2 (Tesfaye et al. 2009; Gebhardt et al. 2011; Regassa et al. 2011; Ekart et al. 2013), FSHR (Regassa et al. 2011; Ekart et al. 2013) and TNFAIP6 (Tesfaye et al. 2009; Gebhardt et al. 2011). All of them are in our list of differentially expressed genes and can be good candidates for biomarkers of oocyte quality and competence. Several genes showed a similar pattern of expression in our microarrays ( $B$. indicus $\times B$. taurus crossbred) and in many other microarray experiments (B. Taurus) focused on the screening of biomarkers for oocyte competence and quality (Table S6); this corroborates that these genes are really in high correlation with oocyte developmental competence.

Among the differentially expressed genes that were identified through microarray analysis, we selected three genes that are up-regulated in the larger follicle's COCs (SRY1, IGFBP4, FGF11) and three genes that are upregulated in the small follicle's COCs (COL18A1, GPC4, ARHGAP22) for qPCR analysis, based on the physiological role and the $P$-value of each candidate gene. All of the selected genes group in the cell cycle category, in which each gene has a distinct and specific role (Table S2), in order to focus on the same metabolic pathway. ARHGAP22 (Rho GTPase activating protein 22) belongs to the Rho-GTPase family, which regulates several aspects of cellular physiology and morphology, such as cell cycle progression, cytoskeleton organization, cell polarity, cell migration and invasion (Ridley 2001; Etienne-Manneville \& Hall 2002). ARHGAP22 stimulates the organization of endothelial cells in capillary tubes during angiogenesis (Katoh \& Katoh 2004). Data regarding the expression of ARHGAP22 in CCs are lacking, but the down-regulation of ARHGAP22 in CCs of larger follicles may be explained by the decreased requirement for angiogenesis due to the end of intensive follicular growth in preparation for ovulation. The COL18A1 gene encodes type XVIII $\alpha 1$ collagen, which is present in the extracellular matrix and is capable of binding and modulating several molecules involved in cell division, polarity and fate, including the Wnt, TGF $\beta$, and FGF families of growth factors (Lin et al. 2001; Aricescu et al. 2002; Quélard et al. 2007). In addition, type XVIII collagen is a component of the basal lamina of the follicle (IrvingRodgers \& Rodgers 2005), and the degradation of collagen fibers is required for follicle rupture during ovulation (Abisogun et al. 1988). Therefore, the down-regulation of the COL18A1 gene is important for the impaired follicle wall resistance that is necessary for its rupture during ovulation. The GPC4 gene is a member of the glypican family, formed by heparin sulfate proteoglycans that are covalently attached to the cell membrane via a glycosylphosphatidylinositol anchor (De Cat \& David 2001; Fico et al. 2011). The glypicans play a role in the regulation of FGF, BMP, and GDF signaling as a low-affinity binding receptor that can modulate the interaction between the signaling molecule and its primary receptor (Hagihara et al. 2000; Nybakken \& Perrimon 2002; Filmus et al. 2007; Watson et al. 2012). The glypican signaling modulation also mediates the expression of the cumulus-specific matrix genes HAS2 and TNFAIP6 (Watson et al. 2012). Interestingly, in our analysis GPC4 (a glypican family member) was down-regulated in $\mathrm{CC}$ from big follicles, and the expression of HAS2 and 
TNFAIP6 was increased as expected according the literature data (Watson et al. 2012). In humans, the differential expression of GPC4 in CCs is correlated with the first embryonic cleavage and, consequently, with high embryonic quality (van Montfoort et al. 2008). Therefore, we also found GPC4 to be a good embryo quality marker candidate because its regulation is related to oocyte competence and it mediates the cumulus-specific matrix genes HAS2 and TNFAIP6, all of them differentially expressed in our arrays.

In larger follicles, the expression of up-regulated genes included IGFBP4, which encodes one of the main IGF binding proteins in the follicular antrum (Buratini et al. 2005). This protein that binds to and sequesters the IGF molecules and modulates follicular deviation and dominance (Fortune et al. 2004), probably through its regulatory effect in steroidogenesis (Kwintkiewicz \& Giudice 2008). High expression of IGFBP4 was found in CCs of women with polycystic ovary syndrome (Kwon et al. 2010) and can inhibit the steroidogenesis in cumulus, granulosa and teca cells (Cataldo \& Giudice 1992; Mason et al. 1997). Because IGFs have various roles during all stages of follicle growth and maturation (Fortune et al. 2001), it is unclear how the up-regulation of IGFBP4 in larger follicles $(\geq 8.0 \mathrm{~mm})$ can contribute to the higher competence of oocytes from this group. FGF11 is also a negative regulator of steroid synthesis and granulose cell survival and is expressed in mouse oocytes and embryos (Zhong et al. 2006), but its expression in CCs has not been documented. Despite the extensive literature regarding the FGF family, there is no information about the role of FGF11 in follicle growth and development. Further investigation is required to determine the role of FGF11 during follicular development and oocyte competence and its potential use as a genetic marker. The sprouty RTK signaling antagonist 1 (SPRY1) gene belongs to a recently discovered gene family with four members (SPRY1-4); it is induced by the FGF family and down-regulates inducers through a negative feedback loop (Faedo et al. 2010). The SPRY family members are strictly expressed in mammals in a specific phase of initial embryo development, and their expression pattern resembles that of the FGF family (Felfly \& Klein 2012). Down-regulation of SPRY1 is associated with angiogenesis in endothelial cells and increased cell proliferation, possibly due to the modulation of $p 21$ and cyclin D1 expression (Sabatel et al. 2009). FGF2 also induces higher levels of SPRY2 mRNA in mouse CCs (Sugiura et al. 2009) and human luteinic-granulosa cells (Haimov-Kochman et al. 2005). The level of SPRY2 mRNA in bovine granulosa cells is also negatively correlated with oocyte developmental competence in experiments using differential display and suppressive subtractive hybridizations (Robert et al. 2001).

In conclusion, we analyzed the expression profile of differentially expressed genes between two distinct populations of bovine CCs associated with oocytes of high and low competence in order to produce healthy IVP embryos.
Through these experiments, a list of 4178 significantly expressed genes was generated for use as biomarkers of oocyte competence and IVP embryo quality. The expression of three down-regulated (COL18A1, GPC4, ARHGAP22) and three up-regulated (SPRY1, IGFBP4, FGF11) candidates was validated by qPCR for use as a marker of oocyte quality and competence for ART. The use of genetic markers from a non-invasive CC biopsy to select the best oocytes has the potential to improve IVF technology for both humans and livestock (Krisher 2003). Also these potential biomarkers can be useful as tools for the improvement of IVF and embryo culture media to increase blastocyst production and quality.

\section{Acknowledgements}

We thank Dr. Carlos J. H. Souza for the helpful revision of this manuscript. This work was supported by Embrapa (project MP1- 01.13.06.001.00.00) and CNPq for Rosana Nishimura scholarship.

\section{References}

Abisogun A.O., Daphna-Iken D., Reich R., Kranzfelder D. \& Tsafriri A. (1988) Modulatory role of eicosanoids in vascular changes during the preovulatory period in the rat. Biology of Reproduction 38, 756-62.

Albertini D.F., Combelles C.M., Benecchi E. \& Carabatsos M.J. (2001) Cellular basis for paracrine regulation of ovarian follicle development. Reproduction 121, 647-53.

Allworth A.E. \& Albertini D.F. (1993) Meiotic maturation in cultured bovine oocytes is accompanied by remodeling of the cumulus cell cytoskeleton. Developmental Biology 158, 101-12.

Aricescu A.R., McKinnell I.W., Halfter W. \& Stoker A.W. (2002) Heparan sulfate proteoglycans are ligands for receptor protein tyrosine phosphatase sigma. Molecular and Cellular Biology 22, 1881-92.

Armstrong D.T. (2001) Effects of maternal age on oocyte developmental competence. Theriogenology 55, 1303-22.

Asirvatham A.J., Magner W.J. \& Tomasi T.B. (2009) miRNA regulation of cytokine genes. Cytokine 45, 58-69.

Assidi M., Dufort I., Ali A., Hamel M., Algriany O., Dielemann S. \& Sirard M.-A.A. (2008) Identification of potential markers of oocyte competence expressed in bovine cumulus cells matured with follicle-stimulating hormone and/or phorbol myristate acetate in vitro. Biology of Reproduction 79, 209-22.

Assidi M., Dieleman S.J. \& Sirard M.-A.A. (2010) Cumulus cell gene expression following the LH surge in bovine preovulatory follicles: potential early markers of oocyte competence. Reproduction 140, 835-52.

Assidi M., Montag M., Van der Ven K. \& Sirard M.-A.A. (2011) Biomarkers of human oocyte developmental competence expressed in cumulus cells before ICSI: a preliminary study. Journal of Assisted Reproduction and Genetics 28, 173-88.

Assou S., Haouzi D., De Vos J. \& Hamamah S. (2010) Human cumulus cells as biomarkers for embryo and pregnancy outcomes. Molecular Human Reproduction 16, 531-8. 
Bauersachs S., Mitko K., Ulbrich S.E., Blum H. \& Wolf E. (2008) Transcriptome studies of bovine endometrium reveal molecular profiles characteristic for specific stages of estrous cycle and early pregnancy. Experimental and Clinical Endocrinology \& Diabetes 116, 371-84.

Bessa I.R., Nishimura R.C., Franco M.M. \& Dode M.A. (2013) Transcription profile of candidate genes for the acquisition of competence during oocyte growth in cattle. Reproduction in Domestic Animals = Zuchthygiene 48, 781-9.

Bettegowda A., Patel O.V., Ireland J.J. \& Smith G.W. (2006) Quantitative analysis of messenger RNA abundance for ribosomal protein L-15, cyclophilin-A, phosphoglycerokinase, beta-glucuronidase, glyceraldehyde 3-phosphate dehydrogenase, beta-actin, and histone H2A during bovine oocyte maturation and early embryogenesis in vitro. Molecular Reproduction and Development 73, 267-78.

Bettegowda A., Patel O.V., Lee K.-B.B., Park K.-E.E., Salem M., Yao J., Ireland J.J. \& Smith G.W. (2008) Identification of novel bovine cumulus cell molecular markers predictive of oocyte competence: functional and diagnostic implications. Biology of Reproduction 79, 301-9.

Brännström M., Bonello N., Norman R.J. \& Robertson S.A. (1995) Reduction of ovulation rate in the rat by administration of a neutrophil-depleting monoclonal antibody. Journal of Reproductive Immunology 29, 265-70.

Brettschneider J., Collin F., Bolstad B.M. \& Speed T.P. (2008) Quality assessment for short oligonucleotide microarray data. Technometrics 50, 279-83.

Brison D.R. (1999) Apoptosis in mammalian preimplantation embryos: regulation by survival factors. Human Fertility 3, 36-47.

Bunel A., Nivet A.L., Blondin P., Vigneault C., Richard F.J. \& Sirard M.A. (2014) Cumulus cell gene expression associated with preovulatory acquisition of developmental competence in bovine oocytes. Reproduction, Fertility, and Development 26, 855-65.

Bunel A., Jorssen E.P., Merckx E., Leroy J.L., Bols P.E. \& Sirard M.A. (2015) Individual bovine in vitro embryo production and cumulus cell transcriptomic analysis to distinguish cumulusoocyte complexes with high or low developmental potential. Theriogenology 83, 228-37.

Buratini J., Teixeira A.B., Costa I.B., Glapinski V.F., Pinto M.G., Giometti I.C., Barros C.M., Cao M., Nicola E.S. \& Price C.A. (2005) Expression of fibroblast growth factor- 8 and regulation of cognate receptors, fibroblast growth factor receptor-3c and -4 , in bovine antral follicles. Reproduction 130, 343-50.

Caixeta E.S., Ripamonte P., Franco M.M., Junior J.B. \& Dode M.A. (2009) Effect of follicle size on mRNA expression in cumulus cells and oocytes of Bos indicus: an approach to identify marker genes for developmental competence. Reproduction, Fertility, and Development 21, 655-64.

Cataldo N.A. \& Giudice L.C. (1992) Insulin-like growth factor binding protein profiles in human ovarian follicular fluid correlate with follicular functional status. The Journal of Clinical Endocrinology and Metabolism 74, 821-9.

Cillo F., Brevini T.A., Antonini S., Paffoni A., Ragni G. \& Gandolfi F. (2007) Association between human oocyte developmental competence and expression levels of some cumulus genes. Reproduction 134, 645-50.

Coticchio G., Sereni E., Serrao L., Mazzone S., Iadarola I. \& Borini A. (2004) What criteria for the definition of oocyte quality? Annals of the New York Academy of Sciences 1034, 132-44.
Cui X. \& Churchill G.A. (2002) Statistical tests for differential expression in cDNA microarray experiments. Genome Biology 4 , 210

De Cat B. \& David G. (2001) Developmental roles of the glypicans. Seminars in Cell \& Developmental Biology 12, 117-25.

Dieleman S.J., Hendriksen P.J., Viuff D. et al. (2001) Effects of in vivo prematuration and in vivo final maturation on developmental capacity and quality of pre-implantation embryos. Theriogenology 57, 5-20

Dode M.A., Dufort I., Massicotte L. \& Sirard M.-A.A. (2006) Quantitative expression of candidate genes for developmental competence in bovine two-cell embryos. Molecular Reproduction and Development 73, 288-97.

Donnison M. \& Pfeffer P.L. (2004) Isolation of genes associated with developmentally competent bovine oocytes and quantitation of their levels during development. Biology of Reproduction 71, 1813-21.

Ekart J., McNatty K., Hutton J. \& Pitman J. (2013) Ranking and selection of MII oocytes in human ICSI cycles using gene expression levels from associated cumulus cells. Human Reproduction 28, 2930-42.

Etienne-Manneville S. \& Hall A. (2002) Rho GTPases in cell biology. Nature 420, 629-35.

Faedo A., Borello U. \& Rubenstein J.L. (2010) Repression of Fgf signaling by sprouty $1-2$ regulates cortical patterning in two distinct regions and times. The Journal of Neuroscience 30, 4015-23.

Fagundes N.S., Michalczechen-Lacerda V.A., Caixeta E.S., Machado G.M., Rodrigues F.C., Melo E.O., Dode M.A. \& Franco M.M. (2011) Methylation status in the intragenic differentially methylated region of the IGF2 locus in Bos taurus indicus oocytes with different developmental competencies. Molecular Human Reproduction 17, 85-91.

Fair T. (2003) Follicular oocyte growth and acquisition of developmental competence. Animal Reproduction Science 78, 203-16.

Fair T., Murphy M., Rizos D., Moss C., Martin F., Boland M.P. \& Lonergan P. (2004) Analysis of differential maternal mRNA expression in developmentally competent and incompetent bovine two-cell embryos. Molecular Reproduction and Development 67, 136-44.

Fair T., Carter F., Park S., Evans A.C. \& Lonergan P. (2007) Global gene expression analysis during bovine oocyte in vitro maturation. Theriogenology 68(Suppl 1), 7.

Felfly H. \& Klein O.D. (2012) Sprouty genes regulate proliferation and survival of human embryonic stem cells. Scientific Reports 3, 2277.

Feuerstein P., Cadoret V., Dalbies-Tran R., Guerif F., Bidault R. \& Royere D. (2007) Gene expression in human cumulus cells: one approach to oocyte competence. Human Reproduction 22 , 3069-77.

Fico A., Maina F. \& Dono R. (2011) Fine-tuning of cell signaling by glypicans. Cellular and Molecular Life Sciences 68, 923-9.

Filmus J., Capurro M. \& Rast J. (2007) Glypicans. Genome Biology 9, 224.

Fortune J.E., Rivera G.M., Evans A.C. \& Turzillo A.M. (2001) Differentiation of dominant versus subordinate follicles in cattle. Biology of Reproduction 65, 648-54.

Fortune J.E., Rivera G.M. \& Yang M.Y. (2004) Follicular development: the role of the follicular microenvironment in selection of the dominant follicle. Animal Reproduction Science, 82-83, 109-26. 
Franco M.M., Fagundes N.S., Michalczechen-Lacerda V.A., Caixeta E.S., de Castro Rodrigues F., Machado G.M., Ferreira A.R. \& Dode M.A. (2014) Characterisation of the methylation pattern in the intragenic $\mathrm{CpG}$ island of the IGF2 gene in Bos taurus indicus cumulus cells during in vitro maturation. Journal of Assisted Reproduction and Genetics 31, 115-20.

Gebhardt K.M., Feil D.K., Dunning K.R., Lane M. \& Russell D.L. (2011) Human cumulus cell gene expression as a biomarker of pregnancy outcome after single embryo transfer. Fertility and Sterility 96, 47-52 e2.

Gérard N., Caillaud M., Martoriati A., Goudet G. \& Lalmanach A.C.C. (2004) The interleukin-1 system and female reproduction. The Journal of Endocrinology 180, 203-12.

Gilchrist R.B. \& Thompson J.G. (2006) Oocyte maturation: emerging concepts and technologies to improve developmental potential in vitro. Theriogenology 67, 6-15.

Gilchrist R.B., Ritter L.J. \& Armstrong D.T. (2004) Oocyte-somatic cell interactions during follicle development in mammals. Animal Reproduction Science, 82-83, 431-46.

Goossens K., Van Poucke M., Van Soom A., Vandesompele J., Van Zeveren A. \& Peelman L.J. (2005) Selection of reference genes for quantitative real-time PCR in bovine preimplantation embryos. BMC developmental biology 5, 27.

Hagihara K., Watanabe K., Chun J. \& Yamaguchi Y. (2000) Glypican-4 is an z-binding heparan sulfate proteoglycan expressed in neural precursor cells. Developmental Dynamics 219, 353-67.

Haimov-Kochman R., Ravhon A., Prus D., Greenfield C., FinciYeheskel Z., S Goldman-Wohl D., Natanson-Yaron S., Reich R., Yagel S. \& Hurwitz A. (2005) Expression and regulation of Sprouty-2 in the granulosa-lutein cells of the corpus luteum. Molecular Human Reproduction 11, 537-42.

Hamel M., Dufort I., Robert C., Gravel C., Leveille M.-C.C., Leader A. \& Sirard M.-A.A. (2008) Identification of differentially expressed markers in human follicular cells associated with competent oocytes. Human Reproduction 23, 1118-27.

Hatzirodos N., Hummitzsch K., Irving-Rodgers H.F., Harland M.L. Morris S.E. \& Rodgers R.J. (2014) Transcriptome profiling of granulosa cells from bovine ovarian follicles during atresia. BMC Genomics 15, 40 .

Heilbrunn L., Daugherty K. \& Wilbur K.M. (1939) Initiation of maturation in the frog egg. Physiological Zoology 12, 97-101.

Hernandez-Gonzalez I., Gonzalez-Robayna I., Shimada M., Wayne C.M., Ochsner S.A., White L. \& Richards J.S. (2006) Gene expression profiles of cumulus cell oocyte complexes during ovulation reveal cumulus cells express neuronal and immunerelated genes: does this expand their role in the ovulation process? Molecular Endocrinology 20, 1300-21.

Huang Z. \& Wells D. (2010) The human oocyte and cumulus cells relationship: new insights from the cumulus cell transcriptome. Molecular Human Reproduction 16, 715-25.

Humblot P., Holm P., Lonergan P. et al. (2005) Effect of stage of follicular growth during superovulation on developmental competence of bovine oocytes. Theriogenology 63, 1149-66.

van den Hurk R. \& Zhao J. (2005) Formation of mammalian oocytes and their growth, differentiation and maturation within ovarian follicles. Theriogenology 63, 1717-51.

Iager A.E., Kocabas A.M., Otu H.H. et al. (2013) Identification of a novel gene set in human cumulus cells predictive of an oocyte's pregnancy potential. Fertility and Sterility 99, 745-52 e6.
Irving-Rodgers H.F. \& Rodgers R.J. (2005) Extracellular matrix in ovarian follicular development and disease. Cell and Tissue Research 322, 89-98.

Katoh M. \& Katoh M. (2004) Identification and characterization of ARHGAP24 and ARHGAP25 genes in silico. International Journal Of Molecular Medicine 14, 333-8.

Krisher R.L. (2003) The effect of oocyte quality on development. Journal of Animal Science, 82(E-Suppl), 23.

Kwintkiewicz J. \& Giudice L.C. (2008) The interplay of insulin-like growth factors, gonadotropins, and endocrine disruptors in ovarian follicular development and function. Seminars in Reproductive Medicine 27, 43-51.

Kwon H., Choi D.-H.H., Bae J.-H.H., Kim J.-H.H. \& Kim Y.-S.S. (2010) mRNA expression pattern of insulin-like growth factor components of granulosa cells and cumulus cells in women with and without polycystic ovary syndrome according to oocyte maturity. Fertility and Sterility 94, 2417-20.

Labrecque R., Vigneault C., Blondin P. \& Sirard M.-A.A. (2013) Gene expression analysis of bovine oocytes with high developmental competence obtained from FSH-stimulated animals. Molecular Reproduction and Development 80, 428-40.

Lee D.L., Kim S.H., Kim E., Chun S.Y. \& Kim T.S. (2009) Interferonalpha is involved in the luteinizing hormone-induced differentiation of rat preovulatory granulosa cells. Journal of Interferon $\mathcal{E}$ Cytokine Research 29, 801-8.

Lequarre A.-S.S., Vigneron C., Ribaucour F., Holm P., Donnay I., Dalbiès-Tran R., Callesen H. \& Mermillod P. (2005) Influence of antral follicle size on oocyte characteristics and embryo development in the bovine. Theriogenology 63, 841-59.

Lin Y., Zhang S., Rehn M., Itäranta P., Tuukkanen J., Heljäsvaara R., Peltoketo H., Pihlajaniemi T. \& Vainio S. (2001) Induced repatterning of type XVIII collagen expression in ureter bud from kidney to lung type: association with sonic hedgehog and ectopic surfactant protein C. Development 128, 1573-85.

Lonergan P., Rizos D., Gutierrez-Adan A., Fair T. \& Boland M.P. (2003) Oocyte and embryo quality: effect of origin, culture conditions and gene expression patterns. Reproduction in Domestic Animals = Zuchthygiene 38, 259-67.

Luchsinger C., Arias M.E., Vargas T., Paredes M., Sanchez R. \& Felmer R. (2014) Stability of reference genes for normalization of reverse transcription quantitative real-time PCR (RT-qPCR) data in bovine blastocysts produced by IVF, ICSI and SCNT. Zygote 22, 505-12.

Mamo S., Carter F., Lonergan P., Leal C.L., Al Naib A., McGettigan P., Mehta J.P., Evans A.C. \& Fair T. (2011) Sequential analysis of global gene expression profiles in immature and in vitro matured bovine oocytes: potential molecular markers of oocyte maturation. BMC Genomics 12, 151.

Mason H.D., Cwyfan-Hughes S., Holly J.M. \& Franks S. (1997) Potent inhibition of human ovarian steroidogenesis by insulinlike growth factor binding protein-4 (IGFBP-4). The Journal of Clinical Endocrinology and Metabolism 83, 284-7.

Misirlioglu M., Page G.P., Sagirkaya H., Kaya A., Parrish J.J., First N.L. \& Memili E. (2006) Dynamics of global transcriptome in bovine matured oocytes and preimplantation embryos. Proceedings of the National Academy of Sciences of the United States of America 103, 18905-10.

van Montfoort A.P., Geraedts J.P., Dumoulin J.C., Stassen A.P., Evers J.L. \& Ayoubi T.A. (2008) Differential gene expression in 
cumulus cells as a prognostic indicator of embryo viability: a microarray analysis. Molecular Human Reproduction 14, 15768.

Mourot M., Dufort I., Gravel C., Algriany O., Dieleman S. \& Sirard M.-A.A. (2006) The influence of follicle size, FSH-enriched maturation medium, and early cleavage on bovine oocyte maternal mRNA levels. Molecular Reproduction and Development 73, 1367-79.

Nybakken K. \& Perrimon N. (2002) Heparan sulfate proteoglycan modulation of developmental signaling in Drosophila. Biochimica et Biophysica Acta 1573, 280-91.

Patel O.V., Bettegowda A., Ireland J.J., Coussens P.M., Lonergan P. \& Smith G.W. (2006) Functional genomics studies of oocyte competence: evidence that reduced transcript abundance for follistatin is associated with poor developmental competence of bovine oocytes. Reproduction 133, 95-106.

Paulini F. \& Melo E.O. (2011) The role of oocyte-secreted factors GDF9 and BMP15 in follicular development and oogenesis. Reproduction in Domestic Animals = Zuchthygiene 46, 354-61.

Pfaffl M.W. (2001) A new mathematical model for relative quantification in real-time RT-PCR. Nucleic Acids Research 29, e45.

Quélard D., Lavergne E., Hendaoui I., Elamaa H., Tiirola U., Heljasvaara R., Pihlajaniemi T., Clément B. \& Musso O. (2007) A cryptic frizzled module in cell surface collagen 18 inhibits Wnt/ beta-catenin signaling. PLoS One, 3, e1878.

Racedo S.E., Wrenzycki C., Herrmann D., Salamone D. \& Niemann H. (2007) Effects of follicle size and stages of maturation on mRNA expression in bovine in vitro matured oocytes. Molecular Reproduction and Development 75, 17-25.

Regassa A., Rings F., Hoelker M., Cinar U., Tholen E., Looft C., Schellander K. \& Tesfaye D. (2011) Transcriptome dynamics and molecular cross-talk between bovine oocyte and its companion cumulus cells. BMC Genomics 12, 57.

Richards J.S. (2007) Genetics of ovulation. Seminars in Reproductive Medicine 25, 235-42.

Ridley A.J. (2001) Rho GTPases and cell migration. Journal of Cell Science 114, 2713-22.

Robert C., Gagné D., Bousquet D., Barnes F.L. \& Sirard M.A. (2001) Differential display and suppressive subtractive hybridization used to identify granulosa cell messenger rna associated with bovine oocyte developmental competence. Biology of Reproduction 64, 1812-20.

Rose-Hellekant T.A., Libersky-Williamson E.A. \& Bavister B.D. (1998) Energy substrates and amino acids provided during in vitro maturation of bovine oocytes alter acquisition of developmental competence. Zygote 6, 285-94.

Russell D.L. \& Robker R.L. (2006) Molecular mechanisms of ovulation: co-ordination through the cumulus complex. Human Reproduction Update 13, 289-312.

Sabatel C., Cornet A.M., Tabruyn S.P., Malvaux L., Castermans K., Martial J.A. \& Struman I. (2009) Sprouty1, a new target of the angiostatic agent $16 \mathrm{~K}$ prolactin, negatively regulates angiogenesis. Molecular Cancer 9, 231.

Su Y.-Q.Q., Sugiura K., Wigglesworth K., O’Brien M.J., Affourtit J.P., Pangas S.A., Matzuk M.M. \& Eppig J.J. (2007) Oocyte regulation of metabolic cooperativity between mouse cumulus cells and oocytes: BMP15 and GDF9 control cholesterol biosynthesis in cumulus cells. Development 135, 111-21.
Sugiura K., Su Y.-Q.Q., Li Q., Wigglesworth K., Matzuk M.M. \& Eppig J.J. (2009) Fibroblast growth factors and epidermal growth factor cooperate with oocyte-derived members of the TGFbeta superfamily to regulate Spry 2 mRNA levels in mouse cumulus cells. Biology of Reproduction 81, 833-41.

Tanghe S., Van Soom A., Nauwynck H., Coryn M. \& de Kruif A. (2002) Minireview: functions of the cumulus oophorus during oocyte maturation, ovulation, and fertilization. Molecular Reproduction and Development 61, 414-24.

Tesfaye D., Ghanem N., Carter F., Fair T., Sirard M.A., Hoelker M., Schellander K. \& Lonergan P. (2009) Gene expression profile of cumulus cells derived from cumulus-oocyte complexes matured either in vivo or in vitro. Reproduction, Fertility, and Development 21, 451-61.

Thompson J.G., Lane M. \& Gilchrist R.B. (2006) Metabolism of the bovine cumulus-oocyte complex and influence on subsequent developmental competence. Society of Reproduction and Fertility Supplement 64, 179-90.

Vozzi C., Formenton A., Chanson A., Senn A., Sahli R., Shaw P., Nicod P., Germond M. \& Haefliger J.A. (2001) Involvement of connexin 43 in meiotic maturation of bovine oocytes. Reproduction 122, 619-28.

Watson L.N., Mottershead D.G., Dunning K.R., Robker R.L., Gilchrist R.B. \& Russell D.L. (2012) Heparan sulfate proteoglycans regulate responses to oocyte paracrine signals in ovarian follicle morphogenesis. Endocrinology 153, 4544-55.

Webb R.J., Marshall F., Swann K. \& Carroll J. (2002) Folliclestimulating hormone induces a gap junction-dependent dynamic change in [cAMP] and protein kinase a in mammalian oocytes. Developmental Biology 246, 441-54.

Wolf E., Arnold G.J., Bauersachs S. et al. (2003) Embryo-maternal communication in bovine: strategies for deciphering a complex cross-talk. Reproduction in Domestic Animals = Zuchthygiene 38, 276-89.

Wolfinger R.D., Gibson G., Wolfinger E.D., Bennett L., Hamadeh H., Bushel P., Afshari C. \& Paules R.S. (2000) Assessing gene significance from cDNA microarray expression data via mixed models. Journal of Computational Biology 8, 625-37.

Xu X., Chen D., Zhang Z., Wei Z. \& Cao Y. (2015) Molecular signature in human cumulus cells related to embryonic developmental potential. Reproductive Sciences 22, 173-80.

Yerushalmi G.M., Salmon-Divon M., Yung Y. et al. (2014) Characterization of the human cumulus cell transcriptome during final follicular maturation and ovulation. Molecular Human Reproduction 20, 719-35.

Zhong W., Wang Q.T., Sun T., Wang F., Liu J., Leach R., Johnson A., Puscheck E.E. \& Rappolee D.A. (2006) FGF ligand family mRNA expression profile for mouse preimplantation embryos, early gestation human placenta, and mouse trophoblast stem cells. Molecular Reproduction and Development 73, 540-50.

\section{Supporting information}

Additional supporting information may be found online in the supporting information tab for this article:

Table S1 Primers used for gene amplification in the qPCR experiment. 
Table S2 Gene clustering according to the Kyoto Encyclopedia of Genes and Genomes KEGG) database, using the bioinformatics tool Database for Annotation, Visualization and Integrated Discovery (DAVID).

Table S3 Up-regulated genes with a $\geq 2.5$ fold change, using the big follicle group as the reference.

Table S4 Down-regulated genes with a $\geq 2.5$ fold change, using the big follicle group as the reference.
Table S5 Complete list of differentially expressed genes $(P<0.05)$ of microarray analysis.

Table S6 List of genes differentially expressed in CCs associated with oocyte competence and consistent with the literature. 